\title{
KETIDAKPATUHAN PESERTA BPJS KESEHATAN MENGIKUTI KEGIATAN PROLANIS DI PUSKESMASRANGAS KABUPATEN MAMUJU
}

\section{NON-COMPLIANCE PARTICIPANTS BPJS HEALTH IN FOLLOWING ACTIVITY PROGRAM OF CHRONIC DISEASE MANAGEMENT (PROLANIS) AT PUSKESMAS}

\author{
Andi Harniati ${ }^{1}$, Suriah ${ }^{2}$, Hasnawati Amqam ${ }^{3}$ \\ ${ }^{1}$ Puskesmas rangas kabupaten mamuju \\ ${ }^{2}$ Promosi Kesehatan, Fakultas Kesehatan Masyarakat, Universitas Hasanuddin \\ ${ }^{3}$ Kesehatan Lingkungan, Fakultas Kesehatan Masyarakat, Universitas Hasanuddin
}

\begin{abstract}
*Alamat Korespondensi : Andi Harniati, Fakultas Kesehatan Masyarakat Universitas HasanuddinJalan Kesejahteraan Selatan VII BTP Blok C No. 258, 081241318337,Email: arnisyahar@yahoo.com
\end{abstract}

\begin{abstract}
ABSTRAK
Program Pengelolaan Penyakit Kronis (PROLANIS) bertujuan mendorong peserta penyandang penyakit kronis (Diabetes Melitus Tipe 2 dan Hipertensi) mencapai kualitas optimal. Penelitian ini bertujuan untuk menganalisis penyebab dari ketidakpatuhan peserta BPJS Kesehatan penyandang penyakit Diabetes Melitus tipe 2 dan Hipertensi dalam mengikuti kegiatan PROLANIS di Puskesmas Rangas Kabupaten Mamuju. Jenis penelitian dengan metode kuantitatif dengan pendekatan cross sectional. Populasi dalam penelitian ini adalah seluruh peserta BPJS kesehatan yang terindikasi menderita penyakit Diabetes Melitus Tipe 2 dan Hipertensi yang terdaftar pada data bulan Juli - Desember 2016 yaitu 42 penderita Diabates eilitus Tipe 2 dan 136 penderita Hipertensi. Penarikan sampel menggunakan simple random sampling sebanyak 130 responden. Pengumpulan data dilakukan dengan menggunakan kuesioner. Uji statistik yang digunakan adalah chi square dan regresi logistik berganda. Hasil menunjukkan bahwa persentase ketidakpatuhan mengikuti kegiatan PROLANIS sebesar 80,8\%. Ada hubungan antara pemahaman tentang instruksi $(97,6 \%, \mathrm{p}=0,000)$, kualitas interaksi $(97,9 \%, \mathrm{p}=0,000)$, dukungan keluarga $(94,9 \%, \mathrm{p}=0,000)$, keyakinan $(95,1 \%, \mathrm{p}=0,000)$, sikap $(93,2 \%, \mathrm{p}=0,000)$ dengan ketidakpatuhan mengikuti kegiatan PROLANIS. Hasil analisis multivariat menunjukkan bahwa kualitas interaksi dan sikap merupakan faktor yang paling dominan dalam hubunganya dengan ketidakpatuhan mengikuti kegiatan prolanis.Penelitian ini menyarankan agar penderita penyakit kronis mengikuti kegiatan PROLANIS karena dapat meningkatkan kualitas hidup penderita dan petugas kesehatan lebih aktif memberikan informasi tentang PROLANIS kepada penderita serta mengajak merekauntuk mengikuti kegiatan PROLANIS.
\end{abstract}

Kata Kunci : prolanis, sikap, kualitas interaksi, keyakinan

\section{ABSTRACT}

The Chronic Disease Management Program (PROLANIS) aims to encourage participants with chronic diseases (Diabetes Mellitus Type 2 and hypertension) to achieve optimal quality of life.This study aims to analyze the causes of non-adherence participants BPJS Health Type 2 Diabetes Mellitus and Hypertension in following activities PROLANIS at Rangas Community Health Center Mamuju District.Type of research with quantitative method with cross sectional approach. The population in this study were all health BPJS participants indicated suffer from Type 2 Diabetes Melitus and Hypertension registered in data from July to December 2016 that is 42 patients Diabetes Melitus Type 2 and 136 patient of Hypertension. Sampling using simple random sampling of 130 respondents. Data collection was done by using questionnaire. The statistical test used is chi square and multiple logistic regression. The results show that the percentage of non-adherence follows PROLANIS activities of $80,8 \%$. There is a relationship between understanding of instructions $(97,6 \% p=0,000)$, quality of interaction (97,9\%, $p=0,000)$, family support $(94,9 \%, p=0,000)$, confidence $(95,1 \%, p=0,000)$, attitude $(93,2 \%, p=0,000)$ with non-compliance following PROLANIS activities. The result of multivariate analysis shows that the quality of interaction and attitude is the most dominant factor in relation with non-adherence following PROLANIS activity. This research suggest that chronic disease patient follow PROLANIS activity because it can improve quality of life of patient and health officer more active giving information about PROLANIS to patient as well invite them to follow PROLANIS activities.

Keywords: prolanis, attitude, quality of interaction, belief. 


\section{PENDAHULUAN}

Penyakit Tidak Menular (PTM) merupakan salah satu tantangan utama bagi kesehatan dan perkembangan di abad ke-21 yang dapat menimbulkan kerugian baik dari segi kesakitan manusia itu sendiri dan kerugian yang ditimbulkan pada sosial ekonomi negara, terutama negara-negara yang berpenghasilan menengah dan rendah. Hampir $75 \%$ (28 juta) kematian akibat PTM dan $82 \%$ kematian dini terjadi di negara dengan penghasilan rendah dan menengah. Penyebab kematian utama akibat PTM di dunia pada tahun 2012 antara lain: penyakit kardiovaskular (46,2\%), kanker (21\%), penyakit pernapasan termasuk asma dan penyakit paru obstruksi kronis $(10,7 \%)$, hipertensi $7 \%$ (28 juta) dan diabetes (4\%) (WHO 2014).

Di Indonesia, prevalensi penyakit Diabetes Melitus (DM) dan Hipertensi cenderung semakin meningkat setiap tahunnya, dimana prevalensi DM dan hipertensi cenderung lebih tinggi terjadi pada perempuan dan laki-laki. Kecenderungan prevalensi DM di Indonesia menurut hasil riskesdas 2013 adalah 2,1 persen, lebih tinggi dibandingkan pada tahun 2007 yaitu sebesar 1,1 persen. Sedangkan kecenderungan prevalensi hipertensi pada tahun 2013 yaitu sebesar 9,5 persen, lebi tinggi dibandingkan 2007 yaitu sebesar 7,6 persen. Propinsi Sulawesi Barat prevalensi penderita DM sebesar 0,8\% dan Hipertensi 22,5\%. (Kemenkes RI, 2013).

Salah satu program promotif preventif penyakti hipertensi dan diabetes melitus dari Badan Penyelenggara Jaminan Sosial (BPJS) Kesehatan adalah Program Pengelolaan Penyakit Kronis (PROLANIS). Sasaran dari program ini adalah seluruh peserta BPJS Kesehatan yang memiliki atau berisiko penyakit Hipertensi dan Diabetes Melitus tipe 2, bertujuan mendorong penyandang penyakit kronis mencapai kualitas hidup optimal(BPJS, 2014).

Salah satu program unggulan untuk meningkatkan kualitas pelayanan kesehatan bagi peserta BPJS Kesehatan serta memudahkan akses pelayanan kesehatan kepada peserta penderita penyakit kronis, maka dilakukan optimalisasi implementasi Program Rujuk Balik. Pelayanan Program Rujuk Balik diberikan kepada peserta BPJS Kesehatan penderita penyakit kronis, khususnya penyakit diabetes melitus dan hipertensi yang sudah terkontrol/stabil namun masih memerlukan pengobatan atau asuhan keperawatan dalam jangka panjang (BPJS Kesehatan, 2014).

Program manajemen penyakit kronis memberikan beberapa keuntungan yang signifikan terhadap peningkatan indikator kesehatan yaitu adanya penurunan biaya akibat berkurangnya jumlag kunjungan ke UGD dan rawat inap RS merupakan outcome kunci dan implikasi penting baik secara praktek dan kebijakan. (Ory et al., 2013); ada peningkatan efikasi diri dan aktifitas fisik bagi penderita penyakit kronis yang berpartisipasi dalam kegiatan program pengelolaan penyakit kronis dibandingkan yang tidak berpartisipasi (Kim \& Young, 2015); kegiatan pengelolaan penyakit kronis dapat menghemat biaya perawatan, meningkatkan kesehatan dan sangat strategis untuk mengatasi epidemi penyakit kronis (Ahn et al., 2013)

Pada saat ini, upaya pencegahan belum menjadi opsi kebanyakan masyarakat. Banyaknya kendala yang menyebabkan ketidakpatuhan penderita DM Tipe 2 dan hipertensi mengikuti kegiatan prolanis. Kurangnya informasi dan kurangnya dukungan emosional dari pasangan, teman-teman dan anggota keluarga (Ganiyu et al., 2013); kesalahan dari pasien dalam memahami instruksi yang diberikan (Brown \& Bussell, 2011); hubungan petugas kesehatan dengan pasien (Khan et al., 2012); keyakinan pasien terhadap pengobatan merupakan prediktor yang kuat dalam ketidakpatuhan (Gadkari \& Horney, 2012); sikap pasien mempunyai peranan dalam menjaga kepatuhan pasien minum obat anti hipertensi (Saleem et al., 2012).

Menyadari tingginya angka
penderita penyakit kronis khusus
penyandang Diabetes dan Hipertensi adalah
masalah di berbagai negara khususnya


indonesia. Ini disebabkan ketidakpatuhan dalam mengikuti berbagai program pengelolaan penyakit kronis, konsekuensi dari ketidakpatuhan penderita adalah kesehatan yang buruk dan adanya peningkatan biaya perawatan kesehatan. Ketidakpatuhan penderita merupakan isu penting dalam kesehatan baik dari perspektif kualitas hidup dan ekonomi Penelitian ini bertujuan untuk menganalisis penyebab dari ketidakpatuhan peserta BPJS Kesehatan penyandang penyakit DM tipe 2 dan Hipertensi dalam mengikuti kegiatan PROLANIS di Puskesmas Rangas Kabupaten Mamuju.

\section{BAHAN DAN METODE}

\section{Lokasi dan Rancangan Penelitian}

Lokasi penelitian di Puskesmas

Rangas Kecamatan Simboro Kabupaten Mamuju pada bulan Maret-Juni. Jenis penelitian yang digunakan yaitu rancangan cross sectional study.

\section{Metode pengumpulan data}

Pada penelitian ini pengumpulan data dilakukan dengan menggunakan kuesioner yang berisi pernyataan terkait ketidakpatuhan peserta BPJS kesehatan mengikuti kegiatan prolanis meliputi faktor pemahaman tentang instruksi, kualitas interaksi, dukungan keluarga, keyakinan dan sikap.

\section{Analisis data}

Analisis data yang dilakukan adalah analisis univariat, biavariat dan multivariat melalui tabulasi silang dan multiple logistic regression dengan menggunakan SPSS for windows 20.0

\section{HASIL PENELITIAN \\ Karakteristik sampel}

\begin{tabular}{lcr}
\multicolumn{1}{c}{ Hasil } & analisis & univariat \\
menunjukkan & distribusi & responden \\
berdasarkan & kelompok & umurnya \\
didominasi oleh responden & yang \\
mempunyai kelompok umur & $50-59$ tahun
\end{tabular}

yaitu 67 responden $(51,5 \%)$, perempuan yaitu 81 responden $(62,3 \%)$ responden yang menderita hipertensi sebanyak 98 responden $(51,5 \%)$, menderita diabetes mellitus (DM) sebanyak 22 responden $(16,9 \%)$ dan menderita hipertensi dan DM sebanyak 10 responden $(7,7 \%)$.

Distribusi responden berdasarkan pemahaman tentang instruksi kurang baik sebanyak 85 responden $(65,4 \%)$, kualitas interaksi kurang baik sebanyak 97 responden $(74,6 \%)$, dukungan keluarga tidak mendukung sebanyak 96 responden $(73,8 \%)$, tidak yakin sebanyak 101 responden $(77,8 \%)$, mempunyai sikap negatif sebanyak 105 responden $(80,8 \%)$, dan lebih banyak tidak patuh mengikuti kegiatan prolanis sebanyak 105 responden $(80,8 \%)$.

Pada Tabel 1 hasil analisis bivariat menunjukkan bahwa responden yang tidak patuh mengikuti kegiatan PROLANIS lebih banyak mempunyai pemahaman tentang instruksi kurang yaitu 97,6\% kualitas interaksi kurang yaitu 97,9\%, dukungan keluarga kurang yaitu 94,9\%, keyakinan kurang yaitu 95,1\% dan sikap negatif yaitu 93,2\%. Hasil uji statistik dengan Continuity Correctionmenunjukkan ada hubungan pemahaman tentang instruksi, kualitas interaksi, dukungan keluarga, keyakinan, dan sikap dengan ketidakpatuhan mengikuti kegiatan PROLANIS $(\mathrm{p}=0,000)$. Tabel 2 memaparkan hasil analisis multivariat menunjukkan bahwa hasil uji statistik dengan regresi logistik berganda diperoleh variabel yang secara simultan berhubungan dengan ketidakpatuhan mengikuti kegiatan prolanis adalah kualitas interaksi $\mathrm{p}=0,019$ $(\mathrm{W}=5,459)$ dan sikap $\mathrm{p}=0,038(\mathrm{~W}=$ 4,285). 
Tabel 1. Hubungan Pemahaman tentang instruksi, kualitas interaksi, dukung keluarga, keyakinan dan sikap dengan ketidakpatuhan mengikuti program prolanis di Puskesmas Rangas Kabupaten Mamuju Tahun 2017

\begin{tabular}{|c|c|c|c|c|c|c|c|}
\hline \multirow{3}{*}{ Variabel Penelitian } & \multicolumn{4}{|c|}{ Ketidakpatuhan mengikuti prolanis } & \multirow{2}{*}{\multicolumn{2}{|c|}{ Total }} & \multirow[b]{3}{*}{$\mathrm{p}$} \\
\hline & \multicolumn{2}{|c|}{ Patuh } & \multicolumn{2}{|c|}{ Tidak patuh } & & & \\
\hline & $\mathrm{n}$ & $\%$ & $\mathrm{n}$ & $\%$ & $\mathrm{n}$ & $\%$ & \\
\hline \multicolumn{8}{|c|}{ Pemahaman tentang instruksi } \\
\hline Baik & 23 & 50,0 & 23 & 50,0 & 46 & 100,0 & \\
\hline Kurang baik & 2 & 2,4 & 82 & 97,6 & 84 & 100,0 & 0,000 \\
\hline \multicolumn{8}{|l|}{ Kualitas interaksi } \\
\hline Baik & 23 & 67,6 & 11 & 32,4 & 34 & 100,0 & \multirow{2}{*}{0,000} \\
\hline Kurang baik & 2 & 2,1 & 94 & 97,9 & 96 & 100,0 & \\
\hline \multicolumn{8}{|l|}{ Dukungan keluarga } \\
\hline Mendukung & 20 & 62,5 & 12 & 37,5 & 32 & 100,0 & \multirow{2}{*}{0,000} \\
\hline Tidak mendukung & 5 & 5,1 & 93 & 94,9 & 98 & 100,0 & \\
\hline \multicolumn{8}{|l|}{ Keyakinan } \\
\hline Yakin & 20 & 71,4 & 8 & 28,6 & 28 & 100,0 & \multirow{2}{*}{0,000} \\
\hline Kurang yakin & 5 & 4,9 & 97 & 95,1 & 102 & 100,0 & \\
\hline \multicolumn{8}{|l|}{ Sikap } \\
\hline Positif & 18 & 66,7 & 9 & 33,3 & 27 & 100,0 & \multirow{2}{*}{0,000} \\
\hline Negatif & 7 & 6,8 & 96 & 93,2 & 103 & 100,0 & \\
\hline
\end{tabular}

Sumber: Data Primer, 2017.

Tabel 2. Faktor yang paling berhubungan dengan ketidakpatuhan mengikuti kegiatan Prolanis di Puskesmas Rangas Kabupaten Mamuju Tahun 2017.

\begin{tabular}{lrrrrrrr}
\hline \multicolumn{1}{c}{ Variabel } & \multirow{2}{*}{ B } & \multirow{2}{*}{ Wald } & \multirow{2}{*}{ Df } & \multirow{2}{*}{ Sig } & \multicolumn{2}{r}{$95 \%$ C.I.for EXP(B) } \\
\cline { 7 - 8 } & & & & & Lower & \multicolumn{1}{c}{ Upper } \\
\hline Pemahaman tentang instruksi & 1,935 & 3,439 & 1 & 0,064 &, 896 & 53,470 \\
Kualitas interaksi & 3,846 & 5,459 & 1 & 0,019 & 1,858 & 1179,718 \\
Dukungan & $-1,812$ & 1,667 & 1 & 0,197 &, 010 & 2,557 \\
Keyakinan & 1,082 &, 879 & 1 & 0,349 & 307 & 28,363 \\
Sikap & 1,799 & 4,285 & 1 & 0,038 & 1,100 & 33,203 \\
Constant & $-1,923$ & 9,363 & 1 & 0,002 & & \\
\hline
\end{tabular}

Sumber: Data Primer, 2017.

\section{PEMBAHASAN}

Hasil penelitian yang dilakukan di Puskesmas Rangas Kabupaten Mamuju menunjukkan bahwa sebagian besar peserta BPJS Kesehatan penderita Diabetes Melitus Tipe 2 dan Hipertensi tidak patuh mengikuti kegiatan PROLANIS. Menurut Niven (2000) faktor yang menyebabkan ketidakpatuhan mengikuti kegiatan prolanis antara lain pemahaman tentang instruksi, kualitas interaksi, dukungan keluarga, keyakinan dan sikap.

Responden yang tidak patuh mengikuti kegiatan prolanis cenderung disebabkan salah paham tentang instruksi yang diberikan oleh petugas kesehatan. Petugas kesehatan memberikan instruksi terlalu banyak akan sulit di ingat oleh penderita Diabetes Melitus
Tipe 2 dan Hipertensi. Menurut Brown \& Bussell (2011), banyak penderita penyakit kronis mengalami kesulitan mengikuti rejimen pengobatan yang telah direkomendasikan kepada penderita karena faktor kesalahan dari pasien dalam memahami instruksi yang diberikan.

Hasil penelitian analisis uji Chi-Square didapatkan hasil nilai $p<\alpha(0,05)$ yang menunjukkan terdapat hubungan yang bermakna antara kualitas interaksi dengan ketidakpatuhan mengikuti kegiatan prolanis. Kualitas interaksi petugas kesehatan dan penderita sangat mempengaruhi derajat kepatuhan dalam menjalani pengobatan dan terapi, dalam hal ini seberapa sering petugas kesehatan memberikan informasi mengenai penyakit dan cara pencegahannya, kesediaan 
petugas kesehatan dalam memberikan penjelasan, memberikan kesempatan kepada penderita bertanya mengenai penyakit yang diderita. Penelitian yang dilakukan oleh Mulyati dkk., (2013) dalam studi kuantitatif menunjukkan bahwa interaksi antara petugas kesehatan dengan pasien merupakan faktor paling dominan mempengaruhi kesuksesan Self Management Behaviour pada pasien hipertensi, bahwa adanya interaksi yang baik antara petugas kesehatan-pasien merupakan prediksi baiknya Self Management Behaviour yang akan meningkatkan kepatuhan.

Berdasarkan hasil analisis uji ChiSquare didapatkan hasil nilai $\mathrm{p}<\alpha(0,05)$ yang menunjukkan terdapat hubungan yang bermakna antara dukungan keluarga dengan ketidakpatuhan mengikuti kegiatan prolanis. Jika penderita tidak mendapatkan dukungan dari keluarga maka penderita Diabetes Militus Tipe 2 dan Hipertensi sangat sulit termotivasi untuk mengikuti kegiatan prolanis. penelitian yang dilakukan oleh penelitian Nisfiani (2014), menyatakan bahwa dalam pelaksanaan diit hipertensi lebih bnayak yang kurang patuh sebagai akibat kurangnya dukungan dari keluarga. Penelitian di Afrika selatan yang mengungkapkan bahwa mereka kurang mendapat dukungan emosional dari pasangan, teman-teman dan anggota keluarga lainnya yang menjadi faktor ketidakpatuhan terhadap diet dan olahraga bagi penderita diabetes tipe 2 (Ganiyu et al., 2013).

Hasil analisis uji Chi-Square didapatkan hasil nilai $\mathrm{p}<\alpha(0,05)$ yang menunjukkan terdapat hubungan yang bermakna antara keyakinan dengan ketidakpatuhan mengikuti kegiatan prolanis. Penderita Diabetes Melitus Tipe 2 dan Hipertensi bila tidak yakin dalam menjalani suatu pengobatan dan terapi maka akan menyebabkan ketidakpatuhan. Penelitian yang dilakukan oleh Gadkari (2012), Keyakinan pasien terhadap pengobatan khususnya persepsi tentang kebutuhan akan obat dan persepsi tentang kemampuanya membeli obat merupakan prediktor yang kuat dalam ketidakpatuhan tanpa niat. Faktor yang menghambat kepatuhan berobat adalah kurangnya kepercayaan dan keyakinan akan kesembuhan dengan berobat ( Bailey \& Kodack., 2011).

Hasil analisis uji Chi-Square didapatkan hasil nilai $\mathrm{p}<\alpha(0,05)$ yang menunjukkan terdapat hubungan yang bermakna antara sikap dengan ketidakpatuhan mengikuti kegiatan prolanis. penelitian yang dilakukan oleh Saleem et al., (2012), menyatakan bahwa sikap pasien mempunyai peranan dalam menjaga kepatuhan pasien tentang obat anti hipertensi diawal atau selama pengobatan. Sikap responden yang negatif ditunjukkan dengan sikap responden yang penderita Diabetes Melitus dengan kepatuhan mengikuti anjuran diet yang telah ditentukan oleh petugas kesehatan (Phitri, 2013). Sikap positif penderita terhadap upaya pencegahan agar penyakit Diabetes Melitus Tipe 2 dan Hipertensi akan menerima dan menerapkan cara pencegahan penyakit tersebut, sedangkan sikap negatif penderita cenderung akan menolak terhadap upaya pencegahan. Sikap merupakan kemampuan internal dari penderita yang sangat berperan dalam mengambil tindakan, sikap terbuka yang diperlihatkan bisa terlihat dari tindakan penderita Diabetes Melitus dan Hipertensi mengikuti kegiatan PROLANIS.

\section{KESIMPULAN DAN SARAN}

Berdasarkan hasil penelitian dapat disimpulkan bahwa ada hubungan antara pemahaman tentang instruksi, kualitas interaksi, dukungan keluarga, keyakinan dan sikap dengan ketidakpatuhan peserta BPJS Kesehatan mengikuti kegiatan PROLANIS $(\mathrm{p}=0,000)$. Berdasarkan analisis regresi logistik faktor yang paling berhubungan dengan ketidakpatuhan mengikuti kegiatan PROLANIS adalah kualitas interaksi dan sikap. Penelitian ini menyarankan agar penderita penyakit kronis mengikuti kegiatan prolanis karena dapat meningkatkan kualitas hidup penderita dan petugas kesehatan lebih aktif memberikan informasi tentang prolanis kepada penderita serta mengajak merekauntuk mengikuti kegiatan PROLANIS. 


\section{DAFTAR PUSTAKA}

Ahn S. et al., (2013). The impact of chronic disease self-management programs: healthcare savings through a community-based intervention. $B M C$ Public Health 2013 13:1141.

BPJS Kesehatan. (2014). PROLANIS (Program Pengelolaan Penyakit Kronis). Jakarta: BPJS Kesehatan.

BaileyC.J. \&KodackM. (2011). Patient adherence to medication requirements for therapy of type 2 diabetes. International journal of clinical practice, 65(3), 314-322.

Brown M.T. \& BussellJ.K. (2011). Medication adherence: WHO cares?. In Mayo Clinic Proceedings (Vol. 86, No. 4, pp. 304-314). Elsevier.

Dinkes Sulbar. (2015). Profil Kesehatan Provinsi Sulawesi Barat. Mamuju: Dinas Kesehatan Provinsi Sulawesi Barat.

Gadkari A.S. \& McHorne C.A. (2012). Unintentional non-adherence to chronic prescription medications: how unintentional is it really? $B M C$ health services research, 12(1), 98.

Ganiyu AB.etal.,(2013). Non-adherence to diet and exercise recommendations amongst patients with type 2 diabetes mellitus attending Extension II Clinic in Botswana. Afr J Prm Health Care Fam Med. 2013;5(1), Art. \#457, 6 pages. http://dx.doi.org/10.4102/ phcfm.v5i1.457

Kemenkes RI. (2013). Riset Kesehatan Dasar, Jakarta: Kementerian Kesehatan

Khan AR.etal,. (2012). Factors contributing to non-compliance among diabetics attending primary health centers in the Al Hasa district of Saudi Arabia. $J$ Fam Community Med 2012;19:26-32.

Kim S.H.\& Youn C.H. (2015). Efficacy of chronic disease self-management program in older Korean adults with low and high health literacy. Asian nursing research, 9(1), 4246.Helduser et al., (2013). Factors associated with successful completion of the chronic disease selfmanagement program by adults with type 2 diabetes. The Journal ofHealth Promotion \& Maintenance, 3(2) 147157.

Mulyati L., Yetti K., \& Sukmarini L. (2013). Analisis Faktor yang Mempengaruhi Self Management Behaviour pada Pasien Hipertensi. Jurnal Keperawatan Padjadjaran, 1(2).

Nisfiani A.D. (2014). Hubungan Dukungan Keluarga Dengan Kepatuhan Diit Hipertensi Pada Lanjut Usia Di Desa Begajah Kecamatan Sukoharjo Kabupaten Sukoharjo (Doctoral dissertation, Universitas Muhammadiyah Surakarta).

Niven N. (2000). Psikologi kesehatan:Pengantar untuk perawat dan profesional kesehatan lain. Jakarta: EGC

Oryet al., (2013). National study of chronic disease self-management: six-month outcome findings. Journal of Aging and Health, 25(7), 1258-1274.

Phitri H. E. (2013). Hubungan Antara Pengetahuan Dan sikap Penderita Diabetes Mellitus Dengan Kepatuhan Diet Diabetes Mellitus Di RSUD AM. Parikesit Kalimantan Timur. Jurnal Keperawatan Medikal Bedah, 1(1).

Saleemet al.,(2012). Drug attitude and adherence: A qualitative insight of patients with hypertension. Journal of Young Pharmacists, 4(2), 101-107.

World Health Organization.(2014). Global Status Report on Noncommunicable Disease,

Switzerland:WHO 